\title{
EVALUATION OF SOME MINERALS AND VITAMINS IN CORD BLOOD FROM RURAL AND URBAN POPULATION OF UDAIPUR REGION
}

\author{
SUMAN JAIN ${ }^{1}$, PRERNA BANSAL ${ }^{2 *}$, RAJNEESH PRAJAPAT ${ }^{1}$, HARSHDEEP JADEJA $^{3}$ \\ ${ }^{1}$ Department of Biochemistry, Pacific Institute of Medical Sciences, Udaipur, Rajasthan, India. ${ }^{2}$ Department of Biochemistry, Government \\ Medical College, Bhilwara, Rajasthan, India. ${ }^{3}$ Department of Obstetrics and Gynecology, Pacific Institute of Medical Sciences, Udaipur, \\ Rajasthan, India. Email: prerna309@gmail.com \\ Received: 27 April 2021, Revised and Accepted: 01 June 2021
}

ABSTRACT

Objective: Vitamins and minerals collectively referred to as micronutrients have important influence on the health of pregnant women and the growing fetus. Pregnancy is related to increase demand of all nutrients and deficiency any of these can affect pregnancy, delivery, and outcome of pregnancy. Disorders in mineral element nutrition and metabolism can lead to wide variety of malformations. Data on mineral values in newborn are very less in contrast to adult. The present study was planned to analyze some of minerals in the umbilical cord blood of rural and urban population and compare them gender wise.

Methods: Our study group consisted of 640 healthy term newborn. The cord blood was collected immediately after a normal delivery. The blood was tested to determine calcium (Ca), magnesium (Mg), Phosphorus (P), Iron (Fe), Vitamins D3, and Vitamin B12.

Results: The results showed that the levels of Ca, Mg, P and Fe, Vitamin D3, and Vitamin B12 were higher in urban population than rural ones. All were statistically significant. The levels of Mg, P, Fe, and Vitamin B12 were lower in female urban neonates as compared to male urban neonates. All were significant when compared sex wise. The trend was same with increased levels of $\mathrm{Mg}$, P, Fe, and Vitamin B12 in females of rural population than cord blood of male rural neonates.

Conclusions: The result showed that rural and urban population also female and male neonates have genetic variation and difference in mineral metabolism.

Keywords: Calcium, Magnesium, Iron, Phosphorus, Vitamin D3, Vitamin B12, Cord blood.

(C) 2021 The Authors. Published by Innovare Academic Sciences Pvt Ltd. This is an open access article under the CC BY license (http://creativecommons.org/ licenses/by/4.0/) DOI: http://dx.doi.org/10.22159/ajpcr.2021v14i7.41909. Journal homepage: https://innovareacademics.in/journals/index.php/ajpcr

\section{INTRODUCTION}

Vitamins and minerals collectively referred to as micronutrients have important influence on the health of pregnant women and the growing fetus [1]. Pregnancy is related to increase demand of all nutrients such as iron (Fe), copper, zinc, magnesium (Mg), Vitamin B12, folic acid, and ascorbic acid and deficiency any of these can affect pregnancy, delivery, and outcome of pregnancy [2]. Disorders in mineral element nutrition and metabolism in embryo are potentially mutagenic and teratogenic and may lead to abortion or a wide variety of malformations. These disorders may give rise to growth retardation and many abnormalities [3]. Some effects may express in later life in the form of psychological, neurological, Carcinogenesis, and even teratogenesis in effects [3].

Fe deficiency results in anemia, which may increase risk of death from hemorrhage during delivery. In developing countries, Fe deficiency anemia in pregnant women ranges from $35 \%$ to $75 \%$ and is recognized as the most common nutritional problem in the world [4,5]. Calcium (Ca) is the $5^{\text {th }}$ most common element and the most prevalent cation found in the body. It is involved in the action of other intracellular messenger, such as cyclic adenosine mono phosphate and inositol 1, 4, 5- triphosphate and thus mediates the cellular response to numerous hormones [5]. It takes part in nerve transmission. $\mathrm{Mg}, \mathrm{Ca}$, and sodium dearrangements are a frequent finding in asphyxiated infants and these abnormalities are significantly associated with poor outcome [5]. Ca and phosphorus (P) are the major component of bones and cartilages [5,6]. Mg is essential for the synthesis of fatty acids and proteins and it is critical in metabolic processes that require energy derived from adenosine tri phosphate [5,7]. Data on mineral values and also on rural population are very less; hence, the study was planned to estimate some minerals in cord blood of neonates from rural and urban population.

\section{METHODS}

The present research was conducted at Geetanjali Medical College and Hospital and Pacific Institute of medical Sciences, Umarda, Udaipur. The ethical permission was taken from the institutional ethics committee. A total of 640 healthy neonates (following healthy normotensive pregnancy) were included in the study which were divided on the basis of environment as rural (370) and urban (270) and further subdivided according to gender (male and females).

\section{Inclusion criteria for mothers}

Healthy mother only on Fe folic acid and Ca supplementation was included in the study.

\section{Exclusion criteria for mothers}

History with alcoholism, smoking hypertension, thyroid disorders, diabetes mellitus, renal diseases, hypercholesterolemia, twins, liver diseases, tuberculosis and asthma, and pregnancy induced hypertension were excluded from the study.

\section{Inclusion criteria for neonates}

Gestational age between 35 and 42 weeks and absence of congenital anomalies were included in the study.

\section{Exclusion criteria for neonates}

Congenital malformations, neonates born to mother with maternal illness, neonates with perinatal problems such as hypoglycemia, 
pathological jaundice, instrumental delivery, including extraction, and neonates with hypoxic ischemic encephalopathy, sepsis were excluded from the study.

After delivery and cord clamping umbilical venous blood was taken from maternal umbilical end. Serum was separated and analyzed for minerals $\mathrm{Ca}, \mathrm{Mg}$, $\mathrm{P}$, and $\mathrm{Fe}$.

\section{Estimations}

The levels of Ca (NA-BAPTA end point method), Mg (Colorimetric end point method), P (Molybdate UV method), and Fe were assayed by Ferrozine method [8-11].

\section{Statistical analysis}

The mean and standard deviation has been used to define data in each group. These data were compared and significance was calculated between rural and urban neonates and also between male and female neonates using unpaired " $\mathrm{t}$ " test. The $\mathrm{p}$-value $<0.05$ was considered as significant and values $<0.001$ were considered as highly significant. GraphPad prism version 6 software was used for analysis.

\section{RESULTS}

Table 1 and Fig. 1 shows comparison between rural and urban population. The results showed lower $\mathrm{Ca}, \mathrm{Mg}, \mathrm{P}, \mathrm{Fe}$, Vitamin D3, and vitaminb12 levels in rural population as compared to urban neonates. The significance of variance showed high significance when compared rural and urban populations. Female rural neonates as compared to male rural neonates showed that $\mathrm{P}, \mathrm{Mg}$, Fe, and Vitamin B12 were higher in female rural neonates as compared to male rural neonates. The $\mathrm{Ca}$ and Vitamin D3 levels were lower in males than female rural neonates in cord blood. Statistical significant differences between mean levels of these minerals in male and female rural population were seen. All the parameters were highly significant when compared between male and female rural neonates. p-values $<0.001$ were highly significant and $<0.05$ were significant but were non-significant if the values were more than 0.05 . The trend was similar in urban population also. The mean levels of $\mathrm{Mg}, \mathrm{Fe}$, and $\mathrm{P}$ were higher in males as compared to female urban neonates. The Ca showed the reverse trend that it was higher in females as compared to male urban neonates. The significant variance between male and female urban neonates was highly significant (p>0.001) (Table 1).

\section{DISCUSSION}

The result showed that metabolism of the body may be due to result of even a fetal or fetal life plays an important role to the mineral metabolism in adult. It also depends on genetic factor or external factors such as environments, nutrition during and before pregnancy, health condition, and also on mother's life style $[12,13]$.

The disorders of minerals may be detected very early in life as in the cord blood serum. The values of concentrations of the studied parameters of minerals may be the result of the influence of genetic or environmental factor. However, evaluation showed high statistical significance, this can be explained by differences in rural and urban lifestyles which is associated with the bigger migration of people, change in diet in the villages and development of the motor industry and mechanization in villages [14].

In cord blood levels obtained by us match with the observation of some workers compared to the values obtained during the $1^{\text {st }}$ days, months, and years of life. This was confirmed by studies conducted by other authors $[15,16]$. The values of concentrations of the studied parameters of minerals may be the result of the influence of genetic or environmental factor. However, evaluation showed high statistical significance; this can be explained by differences in rural and urban lifestyles which is associated with change in diet habitat in the villages and nutritional awareness and lifestyle more calorific food (carbohydrates), poor nutritional status in villages.

In our studies, when analysis of the influence of gender on the concentration of mineral parameters in cord blood of the neonates from urban and rural regions was done. We found higher levels in males as

Table 1: Comparison of mean \pm SD levels of minerals and vitamins in cord blood of male and female, urban and rural neonates

\begin{tabular}{|c|c|c|c|c|c|c|}
\hline \multirow[t]{2}{*}{ Parameters } & \multicolumn{3}{|l|}{ Urban } & \multicolumn{3}{|l|}{ Rural } \\
\hline & Male $(n=130)$ & Female $(n=140)$ & Total $(n=270)$ & Male $(n=216)$ & Female $(n=154)$ & Total $(n=370)$ \\
\hline $\mathrm{Ca} \mathrm{mg} / \mathrm{dL}$ & $9.85 \pm 1.55$ & $10.10 \pm 1.63$ & $9.82 \pm 1.59$ & $9.58 \pm 1.46$ & $10.01 \pm 1.62$ & $8.76 \pm 1.59 *$ \\
\hline Mg mg/dL & $2.36 \pm 0.61$ & $2.0 \pm 0.60$ & $2.91 \pm 0.61$ & $2.44 \pm 0.60$ & $2.40 \pm 0.67$ & $2.42 \pm 0.61^{*}$ \\
\hline P mg/dL & $6.08 \pm 0.92$ & $5.90 \pm 1.21$ & $6.39 \pm 1.07$ & $6.25 \pm 0.98$ & $6.14 \pm 0.95$ & $6.18 \pm 0.97 *$ \\
\hline \multirow[t]{2}{*}{$\mathrm{Fe} \mu \mathrm{g} / \mathrm{dL}$} & $170.31 \pm 49.20$ & $168 \pm 56.3$ & $173.8 \pm 52.73$ & $173.99 \pm 55.29$ & $171.73 \pm 2.07$ & $173.30 \pm 54.35^{*}$ \\
\hline & Male $(n=48)$ & Female $(n=63)$ & Total $(n=111)$ & Male $(n=123)$ & Female $(n=66)$ & Total $(n=189)$ \\
\hline Vitamin-D3 ng/dL & $27.22 \pm 9.55$ & $34.6 \pm 9.69$ & $28.96 \pm 9.63$ & $25.97 \pm 10.37$ & $26.54 \pm 9.28$ & $26.21 \pm 9.90 *$ \\
\hline Vitamin-B12 nmol/mL & $226.76 \pm 45.15$ & $197.0 \pm 46.48$ & $218.2 \pm 45.70$ & $217.93 \pm 49.87$ & $201.17 \pm 55.78$ & $208.27 \pm 52.34 *$ \\
\hline
\end{tabular}

$* \mathrm{p}<0.0001$ highly significant
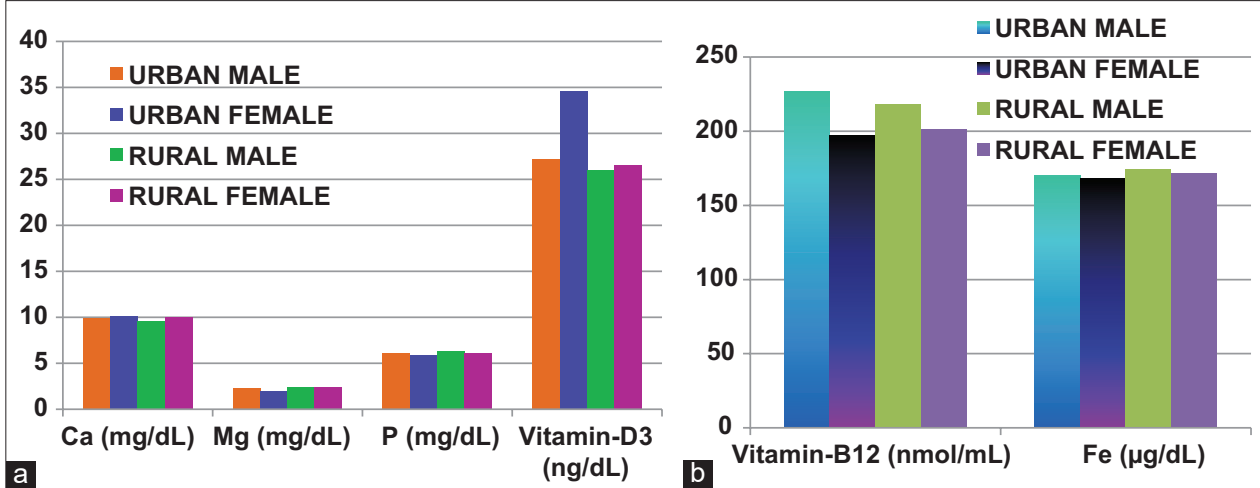

Fig. 1: (a and b) Comparison of mineral and vitamin parameters in rural male and female neonates, urban male and female neonates 
compared to female in rural region. Aderson and Johansen have shown that in healthy term neonates, gender influences the level of lipoprotein we also found difference in levels in male and female but mechanism is not known for mineral mechanism [17]. Hardell also noticed this relationship from the moment of birth and that of the female neonates had a higher concentration of cholesterol and its fraction in the cord blood serum than male newborns [18]. Pac-Kozuchowska (2007) also showed the same trend in rural population [19]. The data for lipid metabolism are available but no studies on mineral metabolism.

In urban population, our studies showed the higher levels than rural (Fig. 1). The reason could be they show aware eating habits, more fruits and vegetables in diet, and good eating habits. The values were significant in our study. Our findings are also in agreement with some previous studies $[15,16]$. The studies to evaluate some minerals and vitamin level in cord blood of neonates from rural and urban population have proved significant difference between the studied groups. The values were significant in our study. In urban nowadays, females are educated and have awareness about diet and nutritional needs during pregnancy. Due to internet facility and literacy in urban ones also makes aware females about diet and other needs during pregnancy.

\section{CONCLUSION}

The result showed that metabolism of the body may be due to result of even a fetal or fetal life plays an important role to the mineral metabolism in adult. It also depends on genetic factor or external factors such as environments, nutrition during and before pregnancy, health condition, and also on mother's lifestyle. The disorders of minerals may be detected very early in life as in the cord blood serum.

\section{AKNOWLEGMENT}

We sincerely thank Pacific Institute of Medical Sciences, Udaipur and Geetanjali Medical College and hospital, Udaipur for extending all the facilities for conducting the work. Authors acknowledge the immense help received from the scholars whose articles are cited and included in references of this manuscript. The authors are also grateful to authors/ editors/publishers of all those articles, journals, and books from where the literature for this article has been reviewed and discussed.

\section{AUTHOR'S CONTRIBUTIONS}

The author declares that all the named authors have contributed equally to this article.

\section{CONFLICTS OF INTEREST}

The authors declare that they have no conflict of interest.

\section{FUNDING}

The research did not receive any specific grant from funding agencies.

\section{REFERENCES}

1. Black RE. Micronutrients in pregnancy. Br J Nutr 2001;85:193S-7.

2. Naeye R, Blanc W, Paul C. Affects of maternal nutrition on human fetus. Pediatrics 1973;52:494-503.

3. McMillan GC. Development of atherosclerosis. Am J Cardiol 1973;31:542-6.

4. World Health Organization. The Prevalence of Anemia in Women: A Tabulation of Available Information. $2^{\text {nd }}$ ed. Geneva: World Health Organization; 1992.

5. Jain S, Gupta AP. Evaluation of some minerals in cord blood from tribal and nontribal population of Udaipur region. Int J Res Med Sci 2016;4:495-8

6. Deshpande N, Patil L, Despande S, Chavan S. Study of ionic calcium in maternal and cord blood and baby's blood at 48-h age. Med J Dy Patil Univ 2014;7:152-5.

7. Bastida S, Vaquero MP, Veldhuizen M, Sanchez-Muniz FJ. Selected trace elements and minerals in cord blood: Association with lipids and lipoproteins at birth. Acta Paediatr 2000;89:1201-6.

8. Wu AH. Teitz Clinical Guide to Laboratory Tests. $4^{\text {th }}$ ed. St. Louis, MO: Saunders Elsevier; 2006. p. 202-7.

9. Mann CK, Yoe JH. Spectophotometric determination of magnesium with 1-azo-2 hydroxy-3-(2,4-dimethy carboannilido)-naphalene-1'-(2hydroxy- benzene-5- sulphonate). Anal Chem 1956;28:202-5.

10. Tietz NW, Rinker AD, Morrison SR. When is a serum iron really a serum iron? A follow up study on the status of iron measurements in serum. Clin Chem 1996;42:109-11.

11. Henry R. Clinical Chemistry: Principles and Technics. $2^{\text {nd }}$ ed. New York: Harper and Row; 1974. p. 723.

12. Jaime-Perez JC, Gomez-Almaguer D. Iron stores in low-income pregnant Mexican women at term. Arch Med Res 2002;33:81-4.

13. Lechtig A. Effects of maternal nutrition on infant health. Implication for action. Nutr Plann 1980;3:1-13

14. Jacobson HN. Weight and weight gain in pregnancy. In: Barness LA, PitKin RM, editors. Clinics in Perinatology. Philadelphia, PA: W B Saunders; 1975. p. 233-6.

15. Pac-Kozuchowska E. The concentration of lipids, lipoproteins and apolipoproteins in cord blood serum of newborns on the course of intrauterine period. Ann UMCS Sec D 2003;2:25-32.

16. Bastida S, Sanchez-Muniz FJ, Cuesta C, Perea S, Aragones A. male and female cord blood lipoprotein profile differences throughout the termperiod. J Perinat Med 1997;25:184-91

17. Anderson GE. Changes in plasma lipoprotein from first day to third week of human life. Prog Clin Biol Res 1985; 188:87-91.

18. Hardell L. Serum lipids and lipoproteins at birth based on a study of 2815 newborn infants. Concentrations and distributions of triglycerides and cholesterol. Acta Pediatr Scan Suppl 1981;285:5-10.

19. Pac-Kozuchowska E. Evaluation of lipids, lipoproteins, apolipoproteins concentration in cord blood serum of newborns from rural and urban environments. Ann Agric Environ Med 2007;14:25-9. 